\title{
Can ReGeneraTing Agents Improve Functional Recovery of Transected Peripheral Nerve through a Nerve Gap Bridged with an Artery Graft?
}

\author{
George Alexopoulos, MD ${ }^{1}$ Leonidas Pavlidis, MD, PhD ${ }^{2}$ Myron Tsagarakis, MD, PhD ${ }^{3}$ \\ Alexandros Delimpaltas, MD ${ }^{2}$ Antonios Tsimponis, $\mathrm{MD}^{2}$ Apostolos Papalois, MD, $\mathrm{PhD}^{4}$ \\ Anna Batistatou, MD, PhD Alexandra Papoudou-Bai, MD ${ }^{5}$ Denis Barritault, MD, $\mathrm{PhD}^{6}$ \\ Efterpi Demiri, MD, $\mathrm{PhD}^{2}$ Georgia Alexandra Spyropoulou, MD, $\mathrm{PhD}^{2}$
}

\footnotetext{
${ }^{1}$ Clinic of Plastic Surgery, Thriasio General Hospital, Magoula Greece

${ }^{2}$ Clinic of Plastic Surgery, School of Medicine, Aristotle University of Thessaloniki, Thessaloniki, Greece

${ }^{3}$ Department of Plastic and Reconstructive Surgery, ENI Medical

Group, Kavos Lefkimi, Corfu, Greece

${ }^{4}$ Department of Research and Development, "ELPEN"

Pharmaceuticals, Athens, Greece

${ }^{5}$ Department of Pathology, Panepistimio loanninon, Ioannina, Greece

6 OTR3 Company, Paris, France
}

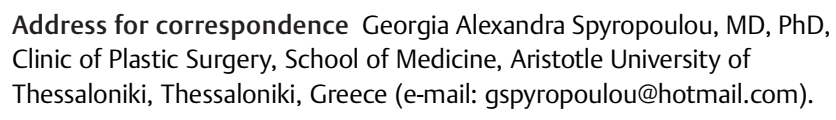

J Reconstr Microsurg Open 2019;4:e47-e53.

\begin{abstract}
Keywords

- peripheral nerve regeneration

- nerve gap

- heparin-binding growth factors

Background The purpose of this study was to use artery grafts filled with CACIPLIQ20 and see if they promote nerve regeneration.

Methods Sixty male Wistar rats were used. The rats were randomly divided into four experimental groups $(n=15)$ : transected control group (negative control group [NCG]), sham-operated group (positive control group [SO]) artery graft group filled with saline (AG/NS), and CACIPLIQ20-treated group (AG/CACIPLIQ20). Fifteen rats were used as artery graft donors. In the $S O$ group, the sciatic nerve was dissected from the surrounding tissues and left intact. In the NCG, AG/NS and AG/CACIPLIQ20) groups, a 10-mm gap was created in the left sciatic nerve. In the NCG group, the gap was not bridged with a graft. In the AG/NS group, the gap was bridged with a graft filled with saline. In the AG/CACIPLIQ20 group, the graft was filled with CACIPLIQ20. Walking track analysis was performed at $4,8,12$, and 16 weeks after surgery. At 16 weeks postoperatively, the rats were sacrificed, nerve sections were harvested for histopathology analysis, and the weight ratio of the gastrocnemius muscle was measured. Results There was no significant difference in myelin sheath thickness between the AG/NS and AG/CACIPLIQ20 groups. Muscle weight in the AG/CACIPLIQ20 group was higher but not statistically significant $(p=0.168)$ compared with the AG/NS group. Also, AG/CACIPLIQ20 mean was better than AG/NS mean, although there was no statistically significant difference $(p=0.605)$.

Conclusion There could be an indication that CACIPLIQ20 improves functional recovery of a transected peripheral nerve through a nerve gap bridged with an artery graft.
\end{abstract}

received

January 23, 2018 accepted after revision April 15, 2019
DOI https://doi.org/

10.1055/s-0039-1692453. ISSN 2377-0813.
Copyright @ 2019 by Thieme Medical Publishers, Inc., 333 Seventh Avenue, New York, NY 10001, USA. Tel: +1(212) 584-4662.
License terms

(c) (1) $\ominus$ (\$) 
Several biomaterial conduits have been used to bridge nerve gaps, ${ }^{1}$ either alone or filled with various substances. ${ }^{2-4}$ Artery grafts present large quantities of laminin and some collagen. These substances are also found in Schwann-cell basal membrane and are reported as axonal outgrowth factors. ${ }^{5}$ Calcipliq20 (OTR3, 4, rue Française 75001 Paris, France) is a product that contains a molecule belonging to the family of the ReGeneraTing Agents (RGTAs). RGTA improves tissue healing in several animal models by stabilizing and protecting heparin-binding growth factors (HBGFs) and matrix proteins. ${ }^{6-8}$ The purpose of this study was to use artery grafts ${ }^{5}$ filled with CACIPLIQ20 and to see if they promote nerve regeneration.

\section{Methods}

Sixty male Wistar rats weighing approximately 280 g were used. The work has been reported in accordance with the ARRIVE (Animals in Research: Reporting In Vivo Experiments) guidelines.

\section{Sample Size Estimation}

It was calculated that a sample size of 15 male Wistar rats per group was required in order to have $90 \%$ probability of demonstrating a between nerve regeneration's biomaterial conduits (AG/NS [5,000] vs. AG/CACIPLIQ20 [6,000]) difference of $>1,000$ (standard deviation [SD]: 650 ) in number of nerve fibers with significance of $<1 \%$ (two-tailed test with Bonferroni correction ).

\section{G-Power Analysis Output}

\begin{tabular}{|c|c|c|}
\hline Analysis: & \multicolumn{2}{|c|}{ A priori: Compute required sample size } \\
\hline \multirow[t]{5}{*}{ Input: } & Tail(s) & $=$ Two \\
\hline & Effect size d & $=1.5384615$ \\
\hline & $\alpha$ err prob & $=0.01$ \\
\hline & Power (1- $\beta$ err prob) & $=0.90$ \\
\hline & Allocation ratio N2/N1 & $=1$ \\
\hline \multirow[t]{7}{*}{ Output: } & Noncentrality parameter $\delta$ & $=4.2132503$ \\
\hline & Critical t & $=2.7632625$ \\
\hline & Df & $=28$ \\
\hline & Sample size group 1 & $=15$ \\
\hline & Sample size group 2 & $=15$ \\
\hline & Total sample size & $=30$ \\
\hline & Actual power & $=0.9166910$ \\
\hline
\end{tabular}

It was calculated that a sample size of $\mathbf{1 5}$ male wistar rats per group was required in order to have $90 \%$ probability of demonstrating a between nerve regeneration's biomaterial conduits [AG/NS( -60) vs. AG/CACIPLIQ20(-45)] difference of > 15 (SD: $10)$ in sciatic nerve function index with significance of $<1 \%$ (two-tailed test with Bonferroni correction).

The rats were randomly divided into four experimental groups $(n=15)$ : transected control group (negative control group [NCG]), sham-operated group (positive control group [SO]) artery graft filled with saline group (AG/NS), and CACIPLIQ20-treated group (AG/CACIPLIQ20). Fifteen rats were used as artery graft donors. The animals were anesthetized with an intramuscular injection of a 3:2 mixture of $100 \mathrm{mg} / \mathrm{dL}$ of

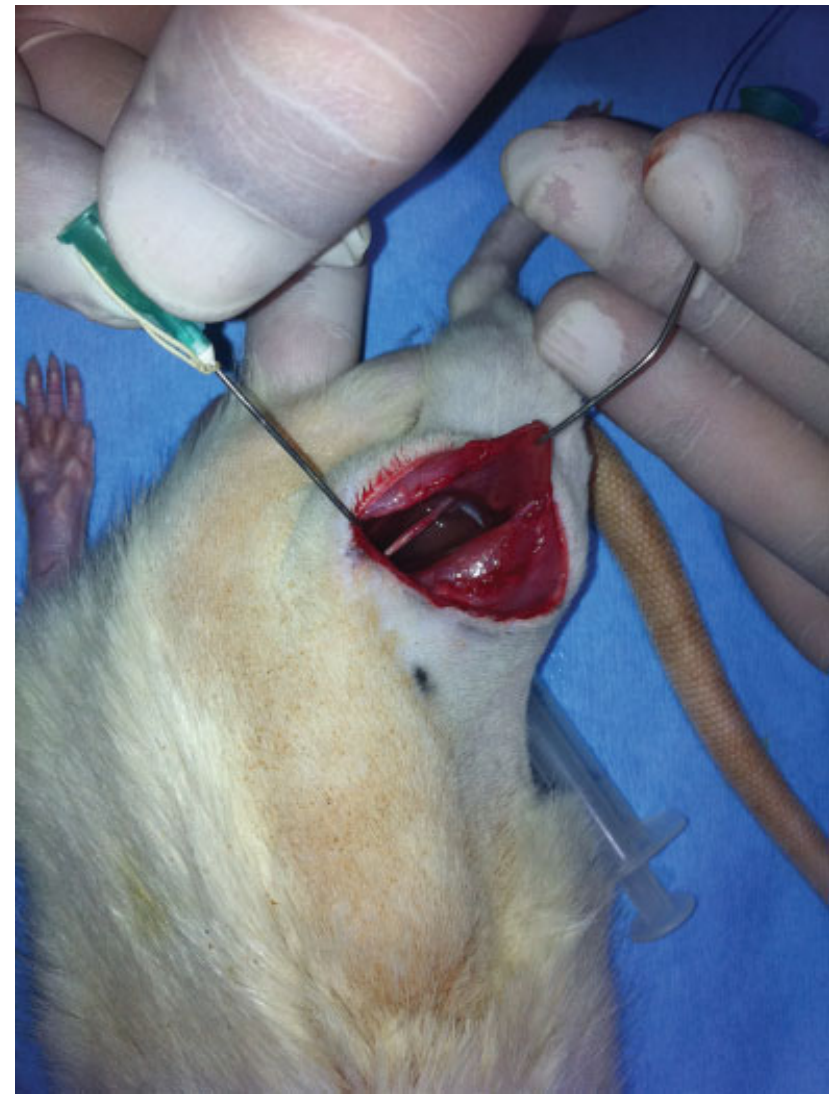

Fig. 1 Exposure of the left sciatic nerve through a gluteal muscle incision.

ketamine hydrochloride and $20 \mathrm{mg} / \mathrm{dL}$ of xylazine hydrochloride. The animals were individually housed, given food and water ad libitum, and exposed to a 12-hour light-dark cycle. The left sciatic nerve was exposed through a gluteal muscle incision ( - Fig. 1). In the transected control group (NCG), the left sciatic nerve was transected proximal to the tibioperoneal bifurcation, where a 7-mm segment was excised, leaving a 10$\mathrm{mm}$ gap due to retraction of nerve ends. Proximal and distal stumps were fixed in the adjacent muscle with a 10-0 nylon

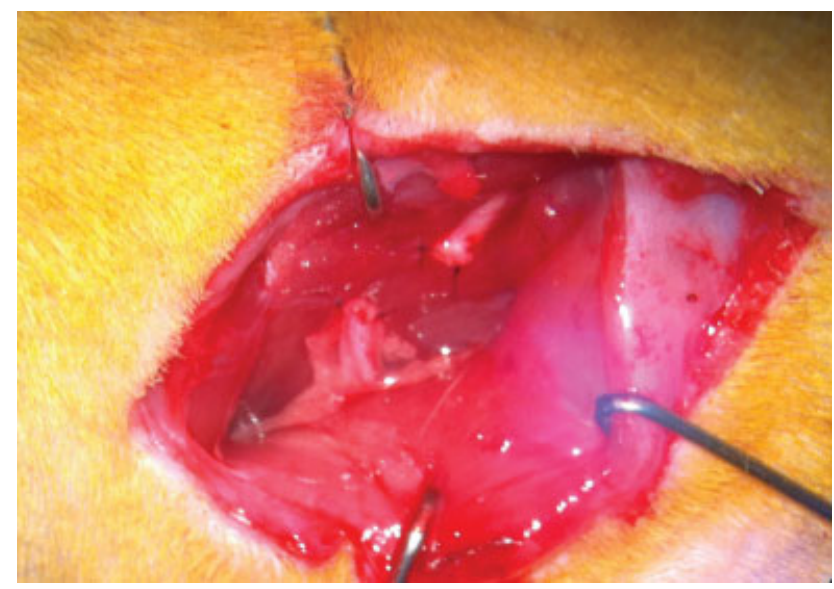

Fig. 2 Excision of a 7-mm segment leaving a 10-mm gap due to retraction of nerve ends in the transected control group (negative control group). Proximal and distal stumps were fixed in the adjacent muscle with a 10-0 nylon epineurial suture. 


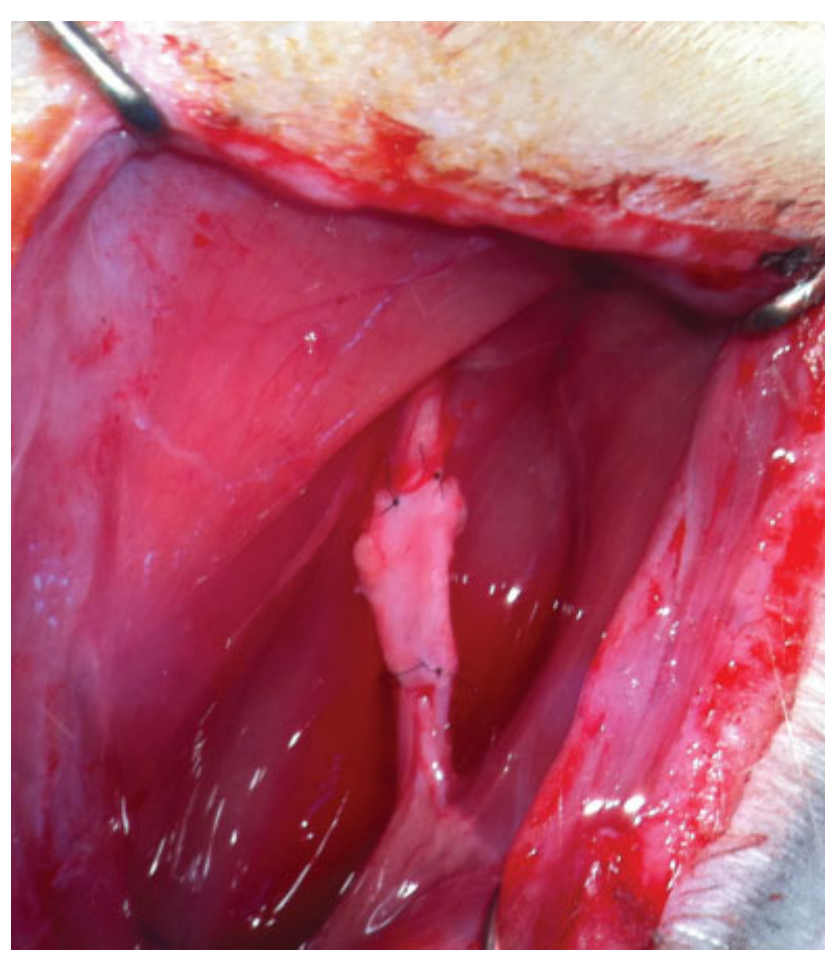

Fig. 3 The gap was bridged using an artery graft filled with saline in the AG/NS group and with CALCIPLIQ in the AG/CALCIPLIQ group, entubulating $2 \mathrm{~mm}$ of the nerve stump at each end.

epineurial suture ( $\mathbf{F i g}$. 2). No graft was interposed between the stumps. In the SO group, the nerve was dissected from surrounding tissues and left intact. In the AG/NS group, a 7-mm nerve segment was resected to produce a 10 - $\mathrm{mm}$ nerve gap after retraction of the nerve transected ends. The gap was bridged using an artery graft filled with saline, entubulating $2 \mathrm{~mm}$ of the nerve stump at each end ( - Fig. 3 ). The artery graft was harvested from the abdominal aorta of donor animals. The abdominal aorta was exposed through a midline abdominal incision (- Fig. 4) and cannulated. Then, a 15-mm segment was harvested on the cannula. Donor animals were sacrificed after graft harvesting. Harvested grafts were washed in physiological solution and left at room temperature for 40 minutes with no preliminary treatment to reduce their antigenicity. Two 10-0 nylon sutures were used to anchor the graft to the epineurium at each end. In the AG/CACIPLIQ20 group, the graft was filled with $10-\mu \mathrm{L}$ CACIPLIQ20.

Walking track analysis was performed at 4, 8, 12, and 16 weeks after surgery based on the method of others. ${ }^{8}$ Recovery assessment was performed using the weight ratio of the gastrocnemius muscles 16 weeks after surgery. Immediately after animal sacrifice, gastrocnemius muscles were dissected and harvested carefully from intact and injured sides and weighed while still wet using an electronic balance.

Finally, immediately after sacrificing (16 weeks after surgery), nerve sections were harvested for histopathology analysis. Nerve sections were fixed in $4 \%$ buffered formalin, cut perpendicular to the longitudinal axis in 2-mm pieces, and embedded in paraffin. Subsequently, $2-\mu \mathrm{m}$-thick serial sections were cut and placed on glass slides. Special stains hematoxylin-eosin and Masson's trichrome, as well as

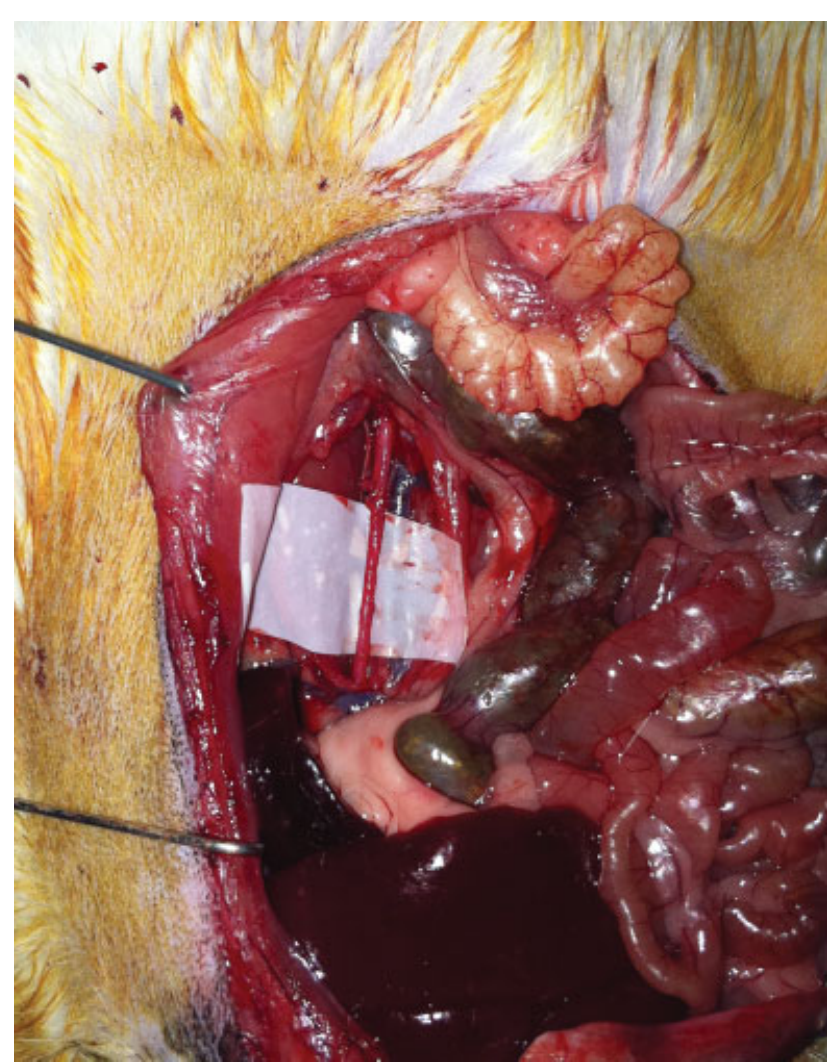

Fig. 4 The artery graft was harvested from the abdominal aorta of donor animals and exposed through a midline abdominal incision.

immunohistochemical stains for S100 protein and neurofilaments (DAKO autostainer, DAB as chromogen) in serial sections were performed. The stained sections were examined under a light microscope, and photographs were taken. For morphometric analysis, the Image-J software (Wayne Rasband, NIH, LOCI, University of Wisconsin, WI) was used. Qualitative features noted included axonal degeneration, empty myelin sheaths, degradation of the myelin sheath, axonal regeneration with sprouting (inside and occasionally outside the graft), and location and intensity of S100 and neurofilament staining. Quantitative information included the number and density of nerve fibers and the diameter of myelin sheath thickness in cross-sections.

\section{Statistical Analysis}

Statistical analysis was conducted through SPSS (edition 23, SPSS Inc.) software package. The Shapiro-Wilk test was used to test normality for the quantitative variables (i.e., SO, AG/NS, NCG, CALC) in consequent times. Data were thoroughly examined and paired samples $t$-test and analysis of variance test for multiple comparisons (Bonferroni) were used to figure out the statistically significant difference between the multiple consecutive measurements of the walking track analysis. The level of statistical significance was determined with $p$-values $<0.05$.

\section{Results}

One animal in the AG/NS group died at the end of the eighth week from infection. This animal was excluded from the study. 


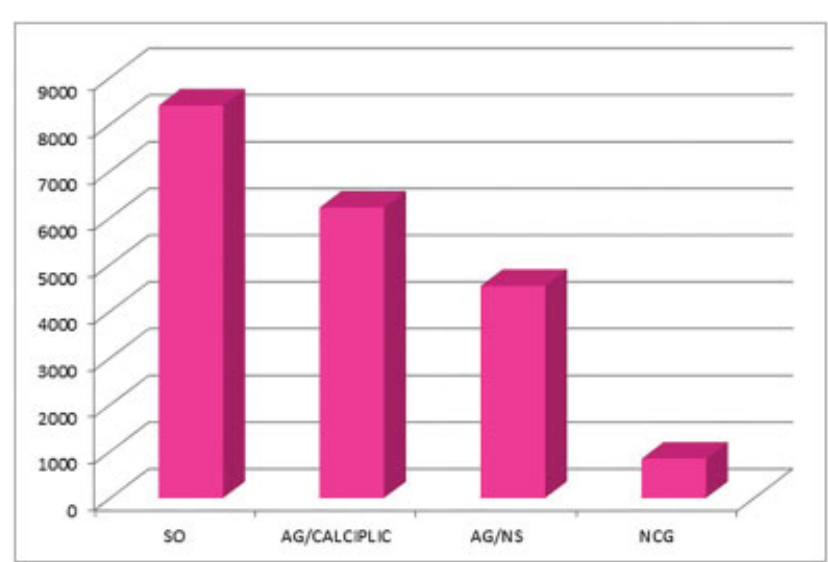

Fig. 5 Mean number of nerve fibers at the end of 16 weeks.

The animal was replaced. Fifteen animals were included in the study from all the groups (AG/NS, NCG, SO, AG/CALCIPLIQ). The mean number of nerve fibers in AG/CACIPLIQ20 group was approximately $74 \%$ in the AG/NS group, $57 \%$ in the SO group, and in NCG group $10 \%$ of the SO group (-Fig 5). There was no significant difference in myelin sheath thickness between the AG/NS and AG/CACIPLIQ20 groups. S100-positive staining was weak and diffuse in the NCG group (evidence for nerve degeneration) and strong and clearly located in the myelin sheath in the AG/NS and AG/CACIPLIQ20 groups, indicating a normal pattern of nerve regeneration. This pattern was verified with neurofilament immunostaining, where regenerated axons were visible in the center of myelin sheaths in the AG/NS and AG/CACIPLIQ20 groups and absent in the NCG group. Interestingly, neurofilament staining was weaker in the AG/NS and AG/CACIPLIQ20 groups compared with the SO group. Regarding gastrocnemius muscle weight, the best results were as expected in the SO group. There was a statistically significant difference between the $\mathrm{SO}$ and $\mathrm{AG} / \mathrm{NS}$ groups $(p=0.000)$ as well as between the SO and AG/CACIPLIQ20 groups $(p=0.000)$. Muscle weight in the NCG group was statistically significant less $(p=0.000)$ compared with that in the SO, AG/NS, and AG/CACIPLIQ20 groups. Muscle weight in the AG/CACIPLIQ20 group was higher but not statistically significant $(p=0.168)$ compared with that in the AG/NS group (results are summarized in - Table 1 ). Regarding walking track analysis, at the end of 4 months, the control (SO) and CALCIPLIQ groups had comparable results $(p=1.000)$ (-Fig. 6). The measurements of the biggest improvement from the first to fourth month was documented in the

Table 1 Muscle weight group statistics

\begin{tabular}{|c|c|c|c|c|c|}
\hline \multirow{16}{*}{$\begin{array}{l}\text { Animal models } \\
\text { muscle weight } \\
\text { (grams) }\end{array}$} & $N$ & $\begin{array}{l}\text { Group A (NCG), } \\
N=15\end{array}$ & $\begin{array}{l}\text { Group B (SO), } \\
N=15\end{array}$ & $\begin{array}{l}\text { Group C (AG/NS), } \\
N=15\end{array}$ & $\begin{array}{l}\text { Group D (CALCI- } \\
\text { PLIQ20), } N=15\end{array}$ \\
\hline & 1 & 0.68 & 3.97 & 1.95 & 1.96 \\
\hline & 2 & 1.17 & 4.17 & 2.28 & 2.25 \\
\hline & 3 & 0.74 & 3.90 & 2.22 & 2.45 \\
\hline & 4 & 0.66 & 2.90 & 1.80 & 1.73 \\
\hline & 5 & 1.17 & 3.79 & 1.90 & 2.15 \\
\hline & 6 & 0.67 & 3.89 & 2.10 & 2.20 \\
\hline & 7 & 0.77 & 3.91 & 0.95 & 2.30 \\
\hline & 8 & 0.69 & 2.89 & 2.02 & 1.77 \\
\hline & 9 & 0.55 & 3.89 & 1.80 & 1.96 \\
\hline & 10 & 0.77 & 3.73 & 1.95 & 2.43 \\
\hline & 11 & 0.61 & 3.54 & 2.17 & 2.28 \\
\hline & 12 & 0.48 & 4.20 & 1.90 & 2.30 \\
\hline & 13 & 0.59 & 4.00 & 0.95 & 1.95 \\
\hline & 14 & 0.65 & 2.59 & 2.05 & 2.07 \\
\hline & 15 & 0.58 & 4.35 & 0.92 & 1.86 \\
\hline $\begin{array}{l}\text { Mean muscle } \\
\text { weight }\end{array}$ & & $0.71 \pm 0.19$ & $3.71 \pm 0.51$ & $1.79 \pm 0.46$ & $2.11 \pm 0.23$ \\
\hline \multicolumn{2}{|l|}{ Group } & $N$ & Mean & $\begin{array}{l}\text { Standard } \\
\text { deviation }\end{array}$ & $\begin{array}{l}\text { Standard error } \\
\text { mean }\end{array}$ \\
\hline \multicolumn{2}{|l|}{ NCG } & 15 & 0.7187 & 0.19982 & 0.05159 \\
\hline \multicolumn{2}{|l|}{ SO } & 15 & 3.7147 & 0.51908 & 0.13403 \\
\hline \multicolumn{2}{|l|}{ AG/NS } & 15 & 1.7973 & 0.46513 & 0.12010 \\
\hline \multicolumn{2}{|l|}{ AG/CALCIPLIQ } & 15 & 2.1107 & 0.23039 & 0.05949 \\
\hline
\end{tabular}

Abbreviations: AG/CACIPLIQ20, artery graft filled with CACIPLIQ20 group; AG/NS, artery graft filled with saline group; NCG, negative control group; SO, sham-operated group. 


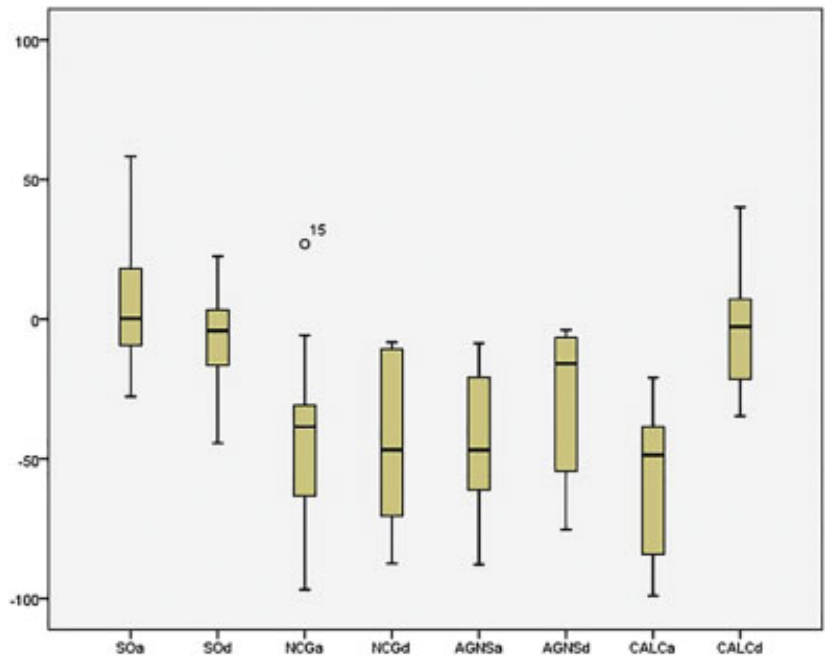

Fig. 6 Walking track analysis results at the end of 4 months.

CALCIPLIQ group $($ mean $=$ CALCIPLIQ $[$ first month $]=-60.63$, mean $=$ CALCIPLIQ [fourth month] $=-3.83 ; p=0.001$ ). The AG/NS group also presented statistically significant improvement from the first to fourth month $(p=0.025)$, less however,
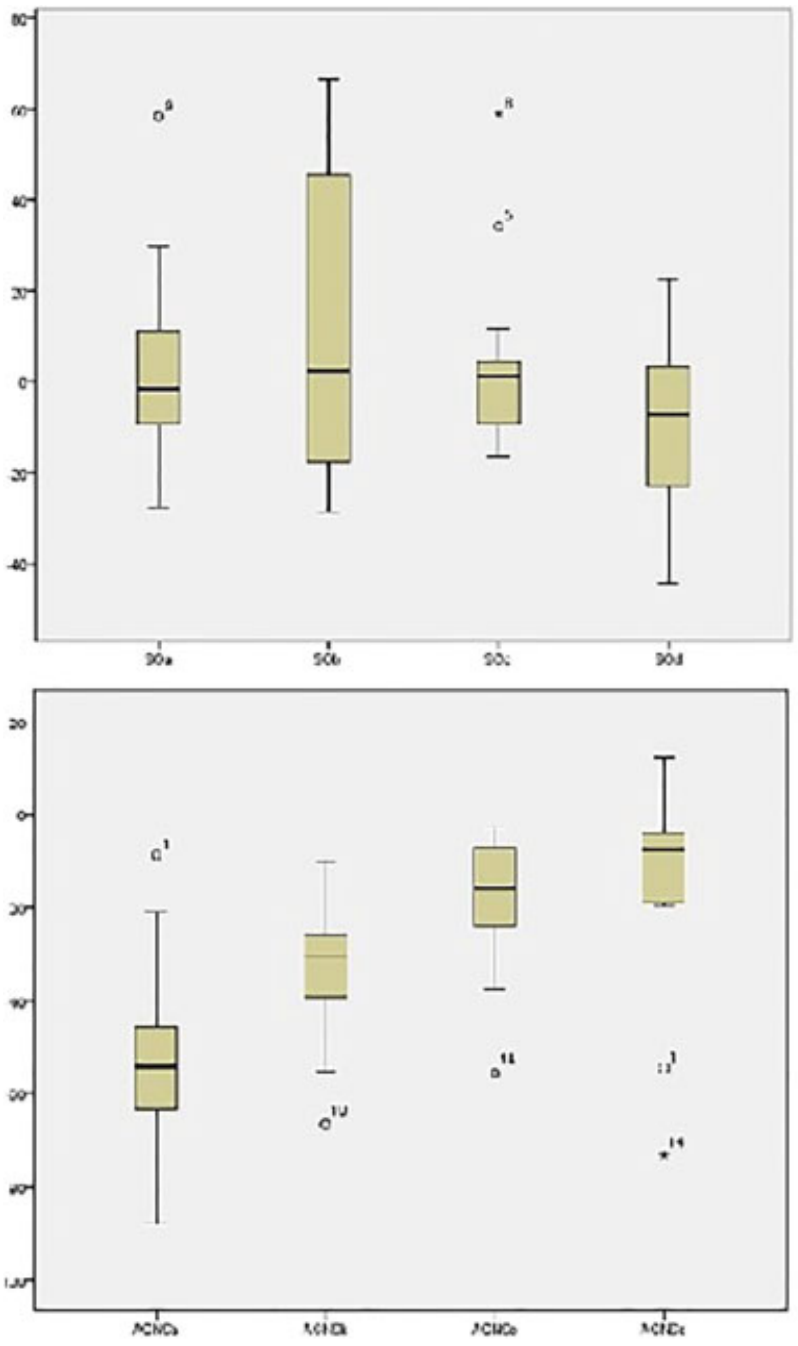

than CALCIPLIQ group ( - Fig. 7). Regarding the fourth month comparison between AG/NS and CALCIPLIQ there was no statistically significant difference $(p=0.605)$; nevertheless, CALCIPLIQ (fourth month) mean was better than AG/NS (fourth month) mean (mean CALCIPLIQ [fourth month] = -3.8385, mean AG/NS [fourth month] $=-20.6321$ ) ( - Fig. 8).

\section{Discussion}

Nerve gaps can result either traumatically or iatrogenically. To repair them, numerous conduits have been used. Silicon tubes were used quite early to bridge nerve gaps ${ }^{9}$ as they have moderate cost and the absence of donor-site morbidity. However, they generate an inflammatory reaction and may cause chronic nerve compression. ${ }^{10}$ To overcome the disadvantages of silicon tubules, biodegradable nerve conduits have been developed. Several materials have been used, such as poly(caprolactone ${ }^{11}$ and copolymers of DLlactide and epsilon-caprolactone [p(DLLA-epsilon-CL)], ${ }^{12}$ either solely as conduits or as tubules, that can synchronously administrate factors to improve the regeneration of peripheral nerves. The disadvantage of biodegradable guides is that they collapse easily. Vein grafts filled with
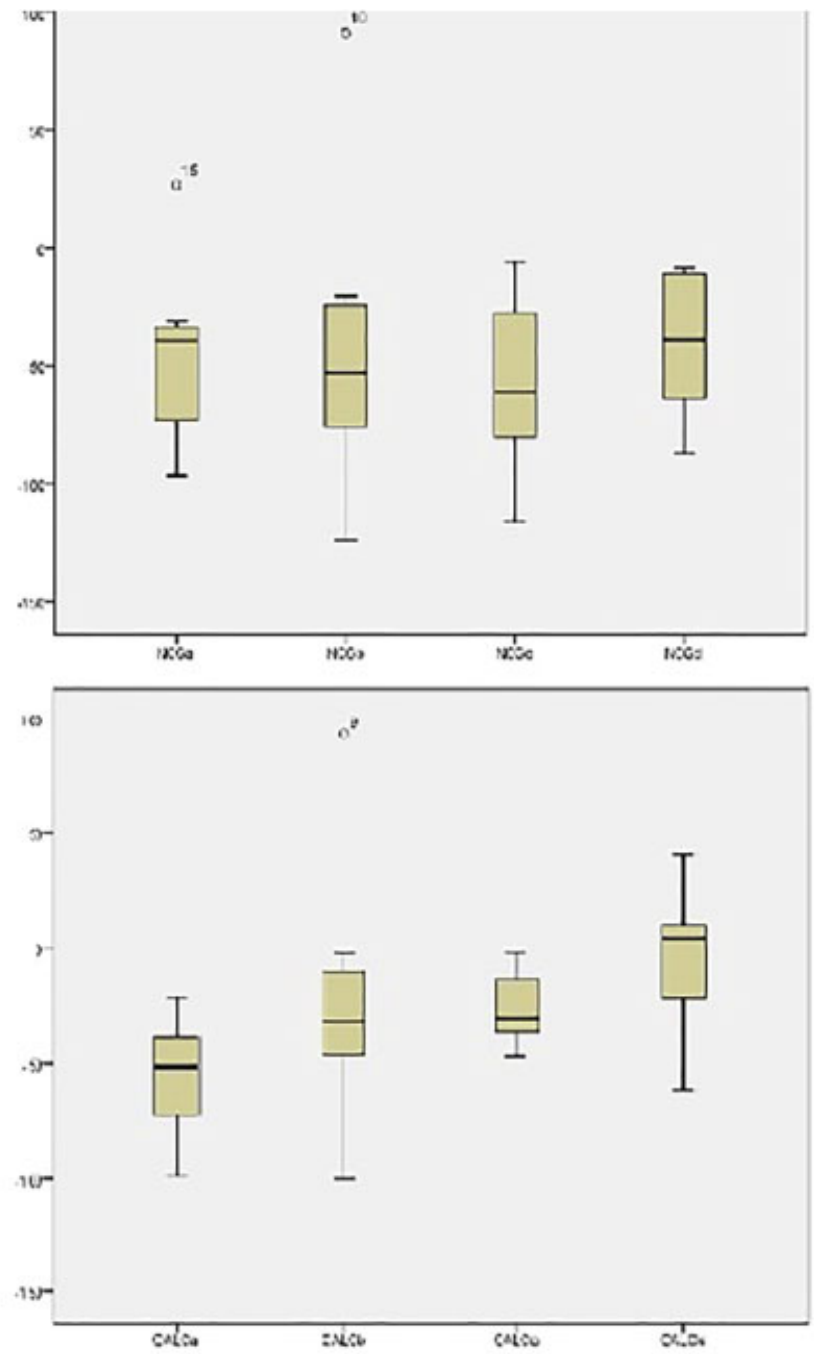

Fig. 7 Walking track analysis results for each group. 


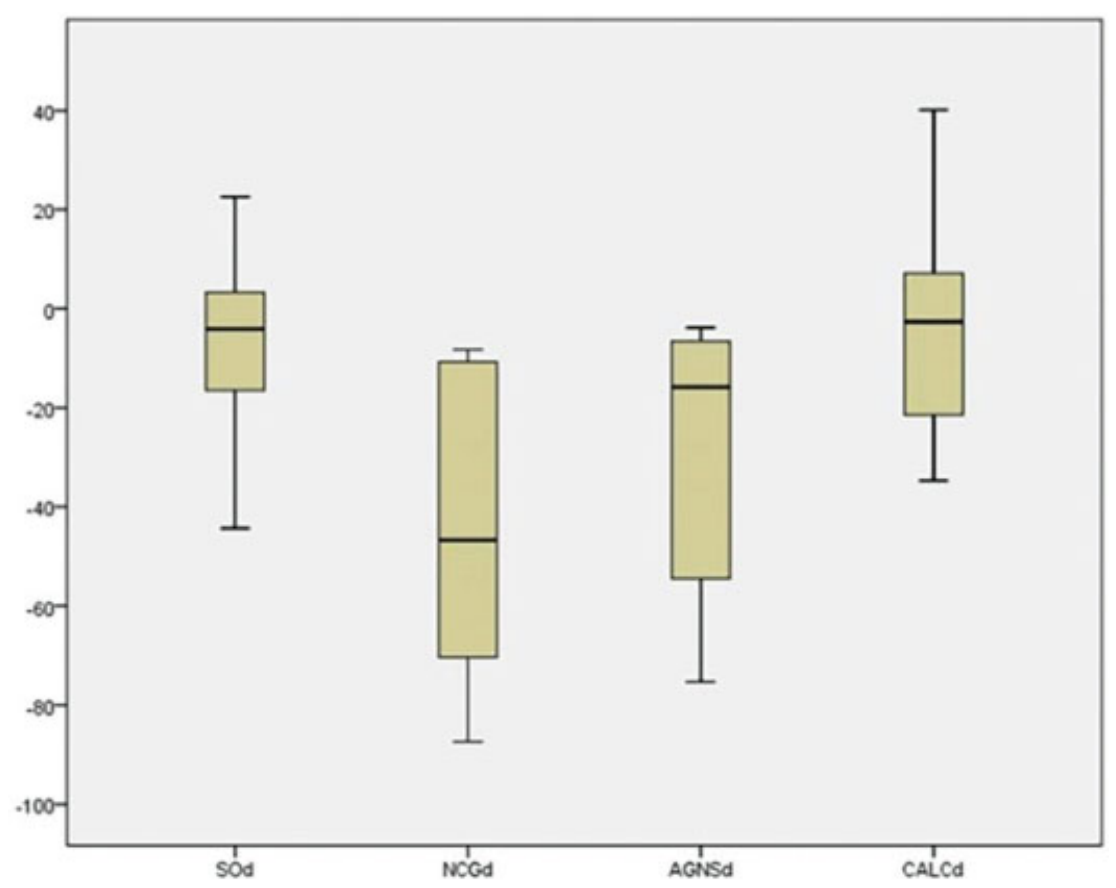

\begin{tabular}{|l|r|r|r|r|r|}
\hline & N & Mnimum & Maximum & Mean & Std. Deviation \\
\hline SO & 14 & $-44,36$ & 22,55 & $-9,6364$ & 18,36479 \\
NCG & 11 & $-87,45$ & $-8,25$ & $-44,8227$ & 28,45267 \\
AGNS & 14 & $-75,35$ & 12,25 & $-20,6321$ & 27,17364 \\
CALC & 13 & $-61,60$ & 40,15 & $-3,8385$ & 29,59382 \\
Valid N (Istwise) & 10 & & & & \\
\hline
\end{tabular}

\section{Comparison of walking track analysis at the end of four months among four groups}

Fig. 8 Comparison of walking track analysis at the end of 4 months among four groups.

muscle are resistant to collapse and provide support to both regenerating axons and migratory Schwann cells. ${ }^{13}$ Artery walls are rigid compared to vein walls and do not need to be filled with muscle to prevent collapse. Moreover, they present quantities of laminin and collagen in analogy to Schwann-cell basal membrane. ${ }^{5}$ Artery grafts have been used previously to bridge nerve gaps in experimental protocols. ${ }^{5}$ RGTAs are biodegradable polymers engineered to mimic heparan sulfate in the extracellular matrix of damaged tissue. CACIPLIQ20 contains a molecule belonging to the family of the RGTAs and has been used to improve tissue healing in both animal models and patients by stabilizing and protecting HBGFs and matrix proteins. ${ }^{6-8}$ Nerve and skin tissue wound-healing process present similarities. ${ }^{14}$ Therefore, we thought of using an agent that promotes skin wound healing and investigating whether it enhances nerve regeneration.

The number of nerve fibers was higher in the AG/CACIPLIQ20 group compared with the AG/NS group. However, arrival of sprouts from the proximal to the distal nerve stump does not necessarily imply recovery of nerve function. ${ }^{15}$
Instead, walking track analysis has frequently been used to reliably determine functional recovery following nerve repair in rat models. Our walking track analysis demonstrated better results in the AG/CACIPLIQ20 group compared with the AG/NS group, although not statistically significant, and this was in accordance with muscle weight results analysis. This could be an indication that CACIPLIQ20 improves functional recovery of a transected peripheral nerve through a nerve gap bridged with an artery graft.

As with any experimental model, however, there are weaknesses. Rigidity of artery grafts has been inculpated to cause excessive pressure on the nerve diameter and hypoxia, thus impairing nerve regeneration. Different grafts and bigger animal models could be used to investigate the efficacy of RGTAs in nerve functional recovery.

\section{Ethical Approval}

None.

\section{Funding}

None. 


\section{Conflict of Interest \\ None declared.}

\section{References}

1 Daly WT, Knight AM, Wang H, et al. Comparison and characterization of multiple biomaterial conduits for peripheral nerve repair. Biomaterials 2013;34(34):8630-8639

2 Ni HC, Tseng TC, Chen JR, Hsu SH, Chiu IM. Fabrication of bioactive conduits containing the fibroblast growth factor 1 and neural stem cells for peripheral nerve regeneration across a $15 \mathrm{~mm}$ critical gap. Biofabrication 2013;5(03):035010

3 Lichtenfels M, Colomé L, Sebben AD, Braga-Silva J. Effect of platelet rich plasma and platelet rich fibrin on sciatic nerve regeneration in a rat model. Microsurgery 2013;33(05):383-390

4 Carriel V, Garrido-Gómez J, Hernández-Cortés P, et al. Combination of fibrin-agarose hydrogels and adipose-derived mesenchymal stem cells for peripheral nerve regeneration. J Neural Eng 2013;10(02):026022

5 Mohammadi R, Hirsaee MA, Amini K. Improvement of functional recovery of transected peripheral nerve by means of artery grafts filled with diclofenac. Int J Surg 2013;11(03):259-264

6 Zakine G, Le Louarn C. Premières applications de la thérapie matricielle en chirurgie plastique et esthétique. Ann Chir Plast Esthet 2010;55(05):421-428
7 Brignole-Baudouin F, Warnet JM, Barritault D, Baudouin C. RGTAbased matrix therapy in severe experimental corneal lesions: safety and efficacy studies. J Fr Ophtalmol 2013;36(09):740-747

8 Yamauchi H, Desgranges P, Lecerf L, et al. New agents for the treatment of infarcted myocardium. FASEB J 2000;14(14):2133-2134

9 Schröder JM, May R, Weis J. Perineurial cells are the first to traverse gaps of peripheral nerves in silicone tubes. Clin Neurol Neurosurg 1993;95(Suppl):S78-S83

10 Merle M, Dellon AL, Campbell JN, Chang PS. Complications from silicon-polymer intubulation of nerves. Microsurgery 1989;10 (02):130-133

11 Ciardelli G, Chiono V. Materials for peripheral nerve regeneration. Macromol Biosci 2006;6(01):13-26

12 Meek MF, Van Der Werff JF, Nicolai JP, Gramsbergen A. Biodegradable $\mathrm{p}$ (DLLA-epsilon-CL) nerve guides versus autologous nerve grafts: electromyographic and video analysis. Muscle Nerve 2001;24(06):753-759

13 Geuna S, Tos P, Battiston B, Giacobini-Robecchi MG. Bridging peripheral nerve defects with muscle-vein combined guides. Neurol Res 2004;26(02):139-144

14 Dellon AL. Wound healing in nerve. Clin Plast Surg 1990;17(03): 545-570

15 Castañeda F, Kinne RK. Omental graft improves functional recovery of transected peripheral nerve. Muscle Nerve 2002;26(04): 527-532 